Ideological Fit Enhances Interpersonal Orientations

William J. Chopik

Michigan State University

Word Count (main text): 4399
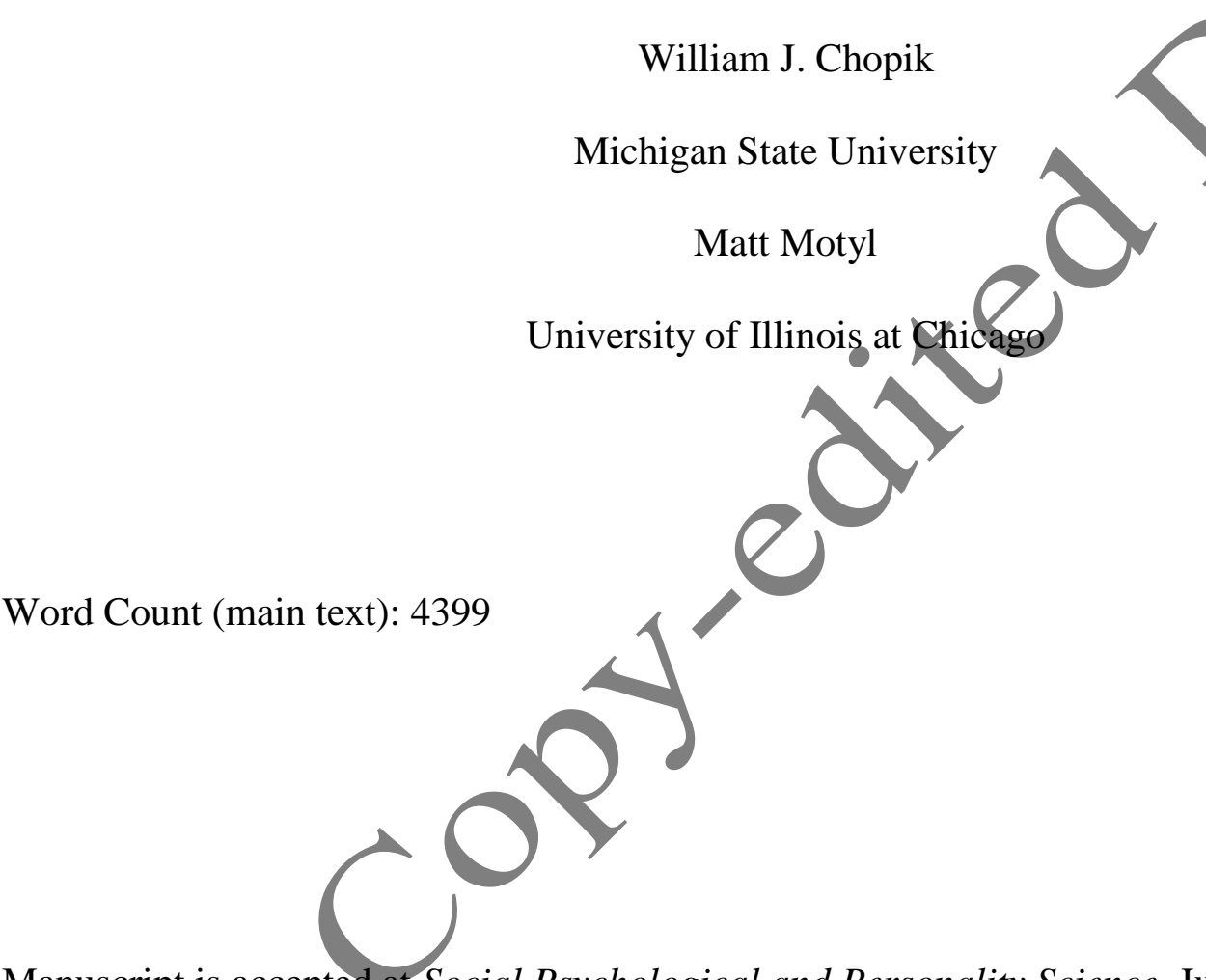

Manuscript is accepted at Social Psychological and Personality Science, June 3, 2016.

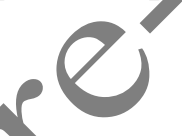

Data from the current manuscript is available at:

https://osf.io/ndk8t/?view_only=ea192b90ca2f470b8a2ea373748ffaa2 


\begin{abstract}
Living among politically dissimilar others leads individuals to feel left out and ultimately predicts mobility away from an area. But does living in politically incongruent environment affect how we relate to other people? In two national samples $(N=12,846$ and $N=6,316)$, the congruence between an individual's ideological orientation and their community's ideological, orientation were examined. Lack of ideological fit with one's environment was assocjated with a difficulty to form close relationships and lower perspective taking. Our findings illustrate the psychological effects of living among dissimilar others and possible explanations for how social environments modulate interpersonal relations.

Abstract word count: 99
\end{abstract}

Keywords: ideology, social ecology, relationships, political misfit, politics, attachment, empathy 


\section{Ideological Fit Enhances Interpersonal Orientations}

"Hell is other people."

-Jean Paul Sartre, No Exit

It is often said that the greatest source of happiness is other people. Other people, however, can also be a source of great misery, particularly if you live among those who dísagree with you politically. Living among dissimilar others leads individuals to feel rejected and ultimately predicts mobility away from an area (McDonald, 2011; Motyl,2014; Motyl, Iyer, Oishi, Trawalter, \& Nosek, 2014; Tam Cho, Gimpel, \& Hui, 2013). Does living among dissimilar others make it difficult to form relationships with other people? The current study examines how being an ideological misfit (e.g., a conservative individual living in a liberal community) is associated with differences in how people connect with others and form close relationships.

People have a fundamental need to belong and enjoy feeling valued by their social group (Baumeister \& Leary, 1995). This need to belong is often reflected in where people choose to live. People tend to migrate to areas yhere their neighbors share similar occupations, ideologies, and even personalities (Florida, 2008; Motyl, 2016; Rentfrow, Gosling, \& Potter, 2008). The characteristics of places - and the people living in them - can also influence individuals to behave in cerfain ways that are socially acceptable to that area (Rentfrow, 2010). Indeed, indicators of political ideology within a community can be seen in the physical and commercial structure of an area (Carney, Jost, Gosling, \& Potter, 2008; Chinni \& Gimpel, 2010). For example, liberal communities tend to have more organic food markets, bicycle trails, and a greater proportion of hybrid automobiles on the road. Conservative communities tend to have larger supermarkets, a higher gun store-to-bookstore ratio, and a greater proportion of sport 
utility automobiles on the road.

What are the psychological effects of living in an area that clashes with your own ideology? In a study conducted shortly after the 2012 election, voters of Mitt Romney (the unsuccessful challenger) expressed a greater desire to move to a different country compared to voters of Barack Obama (the winner). These individuals endorsed such statements as, "The 2012 Presidential election makes me want to leave America" and "I would like to live somewhere else." Further, Romney voters' desires to move to a different country were largely attributable to their reduced sense of belonging (Motyl, 2014). Thus, being reminded that one's community has different political views leaves individuals with a sense of being socially excluded, possibly undermining their well-being.

In the current study, we hypothesized that ideological misfits (e.g., conservatives living in a liberal community) would report greater difficulty depending on and connecting with others. Extant research suggests that living in an area for an extended period of time has the potential to change individuals' personalities (Kling, Ryff, Love, \& Essex, 2003; Oishi, 2010; Rentfrow et al., 2008). Also, ecological theories of interpersonal relationships suggest that the environments that people live in and the quality of their interactions with the inhabitants of those environments shape their dispositions toward other people (Belsky, Steinberg, \& Draper, 1991; Chisholm, 1993). Because hiving among politically dissimilar others is associated with a reduced sense of belonging, ideological misfits may feel as though they cannot reliably depend on the people around them (Motyl, 2014; Motyl et al., 2014). People also tend to dehumanize others who disagree with them politically_denying them of basic human traits like thirst or tactile sensations (Crawford, Modri, \& Motyl, 2013; O’Brien \& Ellsworth, 2012). Further, when ideological disagreement is high, individuals may find themselves arguing more often, are less 
likely to "take the other side's perspective," and as a result, are less likely to feel the support of individuals around them (Bar-Tal \& Halperin, 2010; Bar-Tal, Halperin, \& Pliskin, 2015).

\section{Method}

\section{Participants}

Two data sets were used to test the hypothesis that ideological fit is associated with different dispositions. The two data sources were collected from the website yourmorals.org, which contains a variety of Web studies and individual difference (e.g., personality) measures. All data are available for download at https://osf.io/ndk8t/?view_only=ea192b90ca2f470b8a2ea373748ffaa2.Sample size was chosen by using all available data on attachment orientation and empathy from the YourMorals website at the time of study conception. Thus, no stopping rule was implemented. The sample sizes below enabled us to detect an effect as low as $f^{2}=.0008$ (for Sample 1) and .002 (for Sample 2) at $80 \%$ power.

In the current study, we selected individuals who completed the short-form of the Experiences in Close Relationships-Revised Scale (Sample $1 N=12,846$; Fraley, Waller, \& Brennan, 2000) and another group of individuals who completed the Interpersonal Reactivity Index (Sample $2 N=1,979$, Davis, 1983). We included only individuals who provided geographic information and with complete data on these measures and political orientation.

Sample 1 consisted of 12,846 people $(53.2 \%$ Female; Mage $=37.95, S D=14.69)$.

Participants were $88.4 \%$ Caucasian and primarily identified as liberal (77.4\% liberal, 11.4\% moderate, $11.2 \%$ conservative). Most participants resided in urban areas (90.8\%) but were distributed well across the United States including New England $(n=1,112 ; 8.7 \%$ of the sample), the Pacific Coast $(n=2,697 ; 21.0 \%)$, the Tri-state Area $(n=2,072 ; 16.1 \%)$, Mid- 
Atlantic Region ( $n=1040 ; 8.1 \%)$, the Upper Midwest $(n=2,098 ; 16.3 \%)$, the Plains $(n=574$; 4.5\%), the Rocky Mountain Region ( $n=608 ; 4.7 \%)$, the Southwest $(n=1,009 ; 7.9 \%)$, and the South $(n=1,636 ; 12.7 \%)$. The median level of education is having at least a bachelor's degree.

Sample 2 consisted of 6,316 people (51.5\% Female; Mage $=38.64, S D=15.69)$.

Participants were $88.1 \%$ Caucasian and primarily identified as liberal $(71.2 \%$ liberal, $2.5 \%$ moderate, $16.3 \%$ conservative). Most participants resided in urban areas (89.6\%) bat, as jin Sample 1, were distributed well across the United States including New England $(n=422 ; 6.7 \%$ of the sample), the Pacific Coast $(n=1305 ; 20.7 \%)$, the Tri-state Area $(n=825 ; 13.1 \%)$, MidAtlantic Region $(n=473 ; 7.5 \%)$, the Upper Midwest $(n=1075 ; 17.0 \%)$, the Plains $(n=326$; 5.2\%), the Rocky Mountain Region ( $n=382 ; 6.0 \%)$, the Southwest $(n=634 ; 10.0 \%)$, and the South $(n=874 ; 13.8 \%)$. The median level of education is having at least a bachelor's degree.

\section{Measures}

Attachment Orientation. The 36-item Experiences in Close Relationships-Revised (ECR-R) inventory was used to measure attachment avoidance and anxiety (Fraley et al., 2000). The 18-item ECR-R avoidance subscale reflects an individual's discomfort with closeness. The 18-item ECR-R anxiety subscale reflects an individual's concerns about abandonment. Sample items include "I try to avoid getting too close to others" (avoidance) and "I worry that others won't care about me as much as I care about them" (anxiety). Participants rated the extent to which they agreed with each statement, using a 7-point Likert scale, ranging from 1(disagree strongly) to 7(agree strongly), and the items were averaged to create subscales for avoidance ( $M$ $=2.60, S D=1.12 ; \alpha=.94)$ and anxiety $(M=3.30, S D=1.12 ; \alpha=.91)$.

Empathy. The 28-item Interpersonal Reactivity Index (IRI) was used to measure empathic concern and perspective taking. The 7-item empathic concern subscale reflects a 
person's other-oriented feelings of sympathy for the misfortunes of others, and as such represents an emotional component of empathy. The 7-item perspective taking subscale reflects a person's tendency to imagine others' points of view, and as such represents a cognitive or intellectual component of empathy. Sample items include "When I see someone being treated unfairly, I sometimes don't feel very much pity for them (empathic concern; reverse scored)" and " sometimes try to understand my friends better by imagining how things look from their perspective" (perspective taking). Participants rated the extent to which they agreed with each statement, using a 5-point Likert scale, ranging from 1(does not describe me well) to 7(describes me very well) and the items were averaged to create subscales for empathic concern $(M=3.84$, $S D=.73 ; \alpha=.82)$ and perspective taking $(M=3.67, S D=.72 ; \alpha \neq .81)$.

Two other subscales of empathy, fantasy $(\alpha=.82)$ and personal distress $(\alpha=.83)$, were also presented to participants. However, we did not haye any specific hypotheses about how these dimensions would be associated with ideological fit, and thus are not included in the current report. Upon analyzing these subscales, there was no evidence of ideological fit or misfit for fantasy (political orientation $\times$ community orientation interaction: $p=.44$ ) or personal distress $(p=.81)$.

Political Orientation. Self-reported political orientation was measured on a 7-point Likert-type item ranging from 1(strongly liberal) to 7(strongly conservative) with a midpoint of 4(neutral). Political orientation was comparable in Sample $1(M=2.58, S D=1.44)$ and Sample $2(M=2.83, S D=1.61)$.

Ideological Climate. To ascertain the ideological climate of a participant's community, we followed a similar procedure as Motyl and colleagues (2014). Specifically, the current data sets were combined with Riskind and Motyl's (2012) social climate database which includes 
localized voting behavior (i.e., percentage of an area voting for Senator McCain in the 2008 election) that was matched to participants' zip codes (via Zip Code Tabulation Areas; see Motyl et al., 2014 for more details). The percentage of an area voting for McCain in 2008 was used as a measure of the Republican presence in an area; percentage of an area voting for Obama in 2008 was not used (as it was correlated $r=-.998$ with McCain voting percentage). Percentage voting Republican was comparable in Sample $1\left(N_{Z C T A}=5,616 ; M=38.36, S D=14.37\right)$ and Sample 2 $\left(N_{Z C T A}=3,945 ; M=41.02, S D=14.17\right)$.

\section{Results}

\section{Preliminary Correlations}

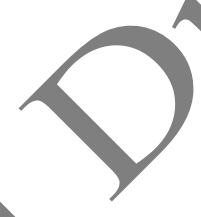

Sample 1. An individual's political orientation and ideological climate were correlated, $r$ $=.17, p<.001$, such that conservative participants tended to five in areas with higher McCain support. Political orientation $(r=-.03, p=.005)$ and ideological climate $(r=-.04, p<.001)$ were negatively related to attachment anxiety, such that conservative participants (compared to liberal participants) and participants living in areas with higher McCain support (compared to lower McCain support) were slightly lower in anxiety. Political orientation $(r=.03, p=.002)$ was positively related to aroidance, such that conservative participants (compared to liberal participants) were slightly higher in avoidance. Ideological climate $(r=-.02, p=.48)$ was unrelated to attachment avoidance. Anxiety and avoidance were significantly intercorrelated, $r=$ $.10, p<.001$.

Sample 2. As in Sample 1, an individual's political orientation and ideological climate were correlated, $r=.18, p<.001$, such that conservative participants (compared to liberal participants) tended to live in areas with higher McCain support. Political orientation was negatively related to perspective taking $(r=-.13, p<.001)$ and empathic concern $(r=-.24, p<$ 
.001 ), such that liberal participants (compared to conservative participants) reported higher perspective taking and empathic concern. Ideological climate was not significantly related to perspective taking $(r=-.02, p=.18)$ and empathic concern $(r=.003, p=.81)$. Empathic concern and perspective taking were significantly intercorrelated, $r=.37, p<.001$.

\section{Multilevel Analyses and Response Surface Plots}

We hypothesized that ideological fit would predict lower avoidance and higher empathic concern. We used multilevel polynomial regressions and response surface plots to analyze relationships among political orientation, ideological climate, and interpersonal orientation (attachment orientation and empathy) (Bleidorn et al., 2016; Edwards, 2002, 2007). Difference score approaches to modeling person-environment fit are limited in many respects, including reduced reliability, ambiguity in interpretation, confounding effects, untested constraints, and dimensional reduction. Multilevel polynomial regressions address these limitations in several ways. In combination with response surface plots, this approach allows for the modeling of three-dimensional relationships between variables, non-linear relationships between variables, and does not suffer the same confounding effects of difference scores because relationships between an outcome (e.g., attachment orientation, empathy) and the constituent parts of a difference score (e.g., bothindividual and community ideology) are modeled simultaneously (see Edwards, 2002; Edwards, 2007, for more details).

Participants are nested in regions (according to ZCTAs). The multilevel polynomial regressions model linear relationships of political orientation and community ideology (i.e., main effects of individual-level political orientation and region-level community ideology), the multiplicative interaction between these two variables (i.e., political orientation $\times$ community ideology), and their quadratic terms (i.e., political orientation ${ }^{2}$ and community ideology ${ }^{2}$ ) in 
predicting interpersonal orientation. Individual age, gender, and education were controlled for in each model.

Attachment anxiety, attachment avoidance, empathic concern, and perspective taking were each transformed into $T$-scores versions of themselves (i.e., standardized scores with a mean of 50 and standard deviation of 10) prior to the multilevel polynomial regressions being run. Transforming interpersonal orientation into T-scores enabled us to use a meaningful, index for effect sizes. Following Cohen's (1988) criteria, a difference of $2 T$-score points and below constitutes a small effect, a difference of $5 T$-score points constitutes a medium effect, and a difference of 8 points constitutes a large effect. Because political orientation and community ideology variables were skewed heavily toward liberal individuals and communities, a rational zero approach was employed (Motyl et al., 2014). For political orientation, "Independent/Moderate" ( scale value $=4$ ) is the conceptual midpoint; for community ideology, $50 \%$ (voting for McCain) is the conceptual midpoint. Scores on these two variables were transformed by subtracting the conceptual midpoint on each scale from the mean scores on each variable, dividing this difference by the standard deviation, and subtracting it from the meancentered standardized score (i.e. for'Sample 1: ZPoliticalOrientation - $|(2.58-4) / 1.44|)$. This transformation gives the conceptual midpoint of each scale a value of 0 . Positive numbers indicate more conservative participants (communities); negative numbers indicate more liberal participants (communities), making the estimates of political orientation and community ideology more interpretable. Worth noting, the results using non-transformed values were nearly identical to the ones presented below with respect to significance level.

We ran four multilevel polynomial regressions predicting each aspect of interpersonal orientation (attachment avoidance, attachment anxiety, perspective taking, and empathic 
concern). We then used the coefficients from the polynomial regressions to create four response surface plots. These surface plots allowed us to visualize the interrelations between variables in a three dimensional space to more accurate decompose any observed interactions. Multi-level analyses were conducted using the SPSS Mixed procedure (Peugh \& Enders, 2005) that controlled for the non-independence that arose from individuals living in the same region; surface plots were created using the RSA package in R (Schönbrodt, 2016).

Sample 1. The results from the multi-level analyses for attachment avoidance can be seen in Table 1. The linear and quadratic effect of political orientation was significant, such that moderate participants were higher in attachment avoidance compared to liberal and conservative participants. There was a significant political orientation $\times$ community ideology interaction predicting avoidance. As seen in Figure 1a, avoidance was lower among liberals living in areas with lower support for McCain compared to liberals liying in areas with higher support for McCain. Avoidance was also lower for conservatives living in areas with higher support for McCain and higher for conservatives living in areas with lower support for McCain.

Table 1. Multi-level models predicting attachment avoidance

\begin{tabular}{|c|c|c|c|c|c|c|c|}
\hline & $b$ & $S E$ & $Z$ & $p$ & \multicolumn{2}{|c|}{$95 \% \mathrm{CI}(6)$} & \\
\hline Intercept & 54.011 & .399 & 135.330 & $<.001$ & LB & UB & $r$ \\
\hline Political Orientatio & -.321 & .126 & -2.552 & .011 & -.569 & -.075 & -.02 \\
\hline Community Ideology & -.129 & .160 & -.811 & .417 & -.442 & .183 & -.01 \\
\hline Pol Orientation $\times$ Comm Ideology & -.289 & .097 & -2.996 & .003 & -.479 & -.100 & -.03 \\
\hline Political Orientation ${ }^{2}$ & -.300 & .080 & -3.753 & $<.001$ & -.457 & -.144 & -.04 \\
\hline Community Ideology ${ }^{2}$ & .125 & .073 & 1.728 & .084 & -.017 & .268 & .05 \\
\hline Age & -.029 & .007 & -4.341 & $<.001$ & -.042 & -.016 & -.04 \\
\hline Gender & -.460 & .095 & -4.840 & $<.001$ & -.646 & -.274 & -.05 \\
\hline Education & -.398 & .049 & -8.050 & $<.001$ & -.495 & -.301 & -.08 \\
\hline
\end{tabular}

Note. Gender: -1: Female, 1: Male. 


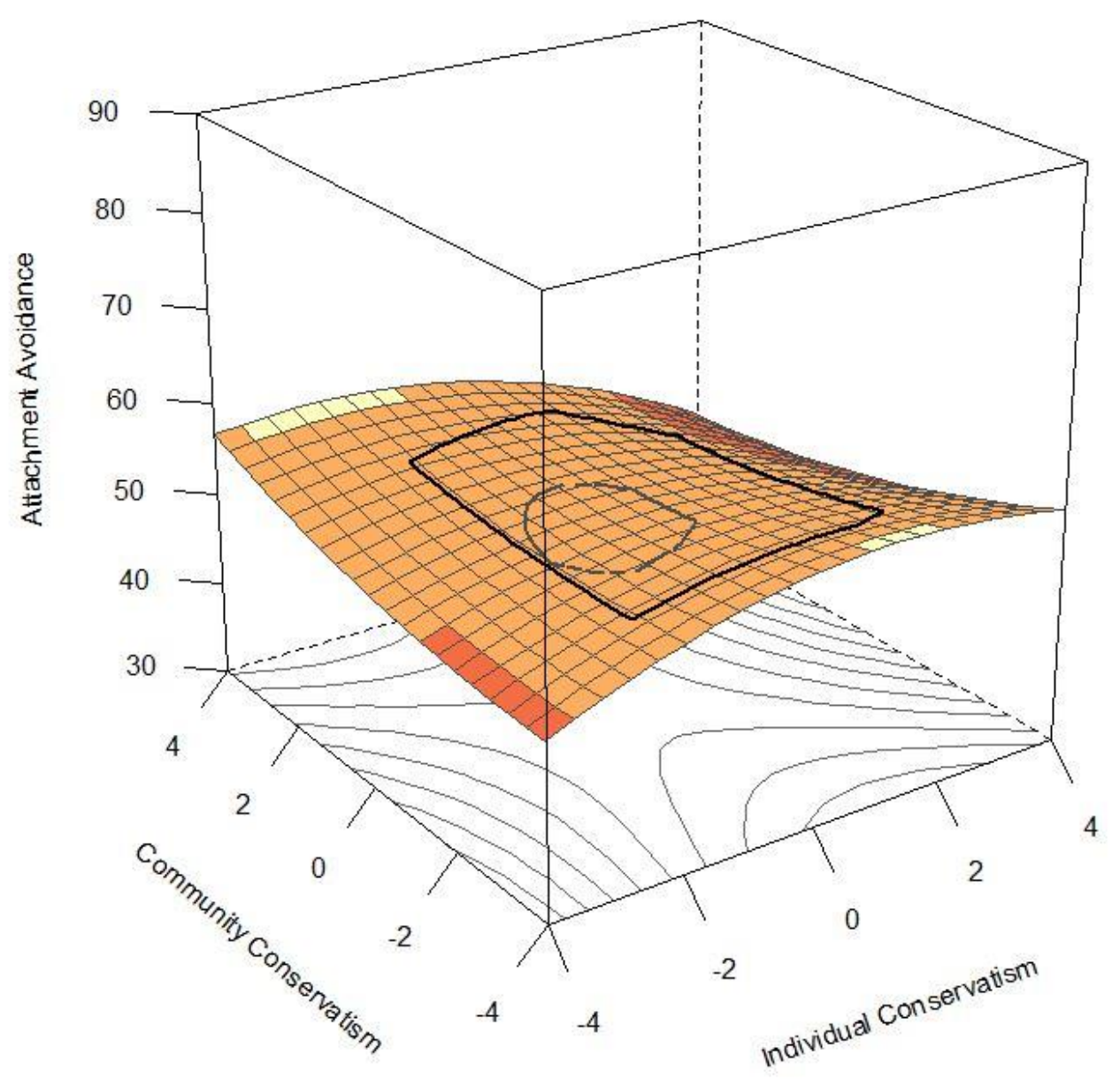

Figure 1a. Response surface plot for attachment avoidance. Plots are based on multilevel pølynomial regression analyses. Outer ellipses represent the range of actual data, so interpretation should be limited to this range. The inner ellipses show the inner $50 \%$ of the points (a bivariate extension of a boxplot; Rousseeuw, Ruts, \& Tukey, 1999). 
The results from the multi-level analyses for attachment anxiety can be seen in Table 2 .

The quadratic effect of community ideology was significant, such that people living in areas with higher and lower levels of McCain support reported lower levels of anxiety compared to people living in areas with equal support for McCain and Obama (see Figure 1b). The political orientation $\times$ community ideology interaction was not significant, suggesting that the aforementioned pattern was true among both liberals and conservatives.

Table 2. Multi-level models predicting attachment anxiety

\begin{tabular}{|c|c|c|c|c|c|c|c|}
\hline & $b$ & $S E$ & $Z$ & $p$ & $95 \%$ & $\mathrm{CI}(6)$ & \\
\hline Intercept & 55.844 & .393 & 141.925 & .00 & $\mathrm{YLB}$ & UB & $r$ \\
\hline Political Orientation & -.139 & .124 & -1.177 & & -.383 & .105 & -.01 \\
\hline Community Ideology & .254 & 157 & 1.616 & & -.054 & .562 & .02 \\
\hline Pol Orientation $\times$ Comm Ideology & 127 & .095 & & .181 & -.059 & .314 & .01 \\
\hline Political Orientation ${ }^{2}$ & -.006 & .079 & & .935 & -.161 & .148 & -.001 \\
\hline Community Ideology ${ }^{2}$ & .256 & .071 & 3.614 & $<.001$ & .117 & .395 & .09 \\
\hline Age & -.133 & .006 & -20.083 & $<.001$ & -.146 & -.120 & -.19 \\
\hline Gender & .096 & .094 & 1.022 & .307 & -.088 & .280 & .01 \\
\hline Education & -.188 & .049 & -3.854 & $<.001$ & -.284 & -.092 & -.04 \\
\hline
\end{tabular}

Note. Gender: -1: Female, 1: Male. 


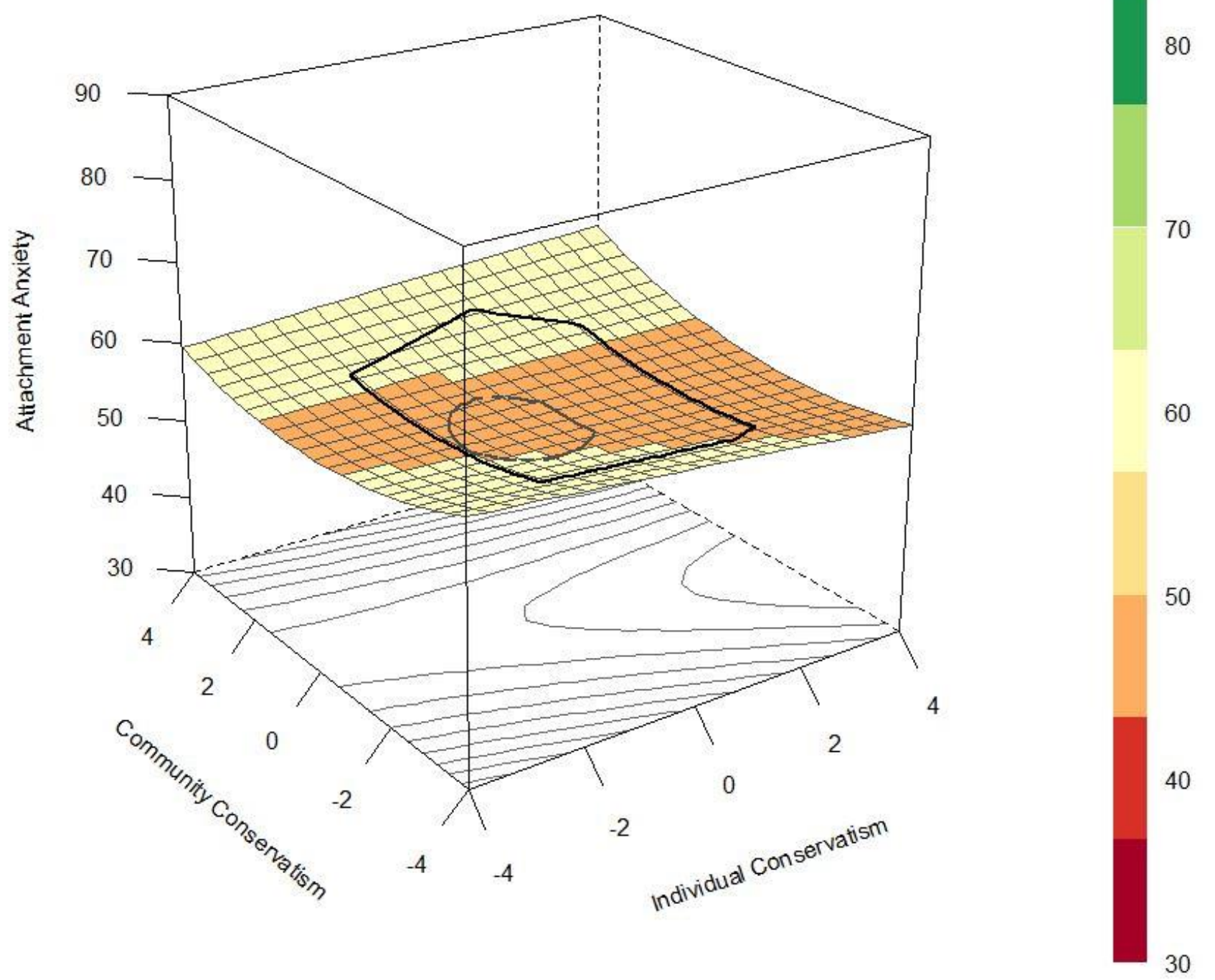

Figure 1b. Response surface plot for attachment anxiety. Plots are based on multilevel polynomial regression analyses. Outer ellipses represent the range of actual data, so interpretation should be limited to this range. The inner ellipses show the inner 50\% of the points (a bivariate extension of a boxplot; Rousseeuw, Ruts, \& Tukey, 1999). 


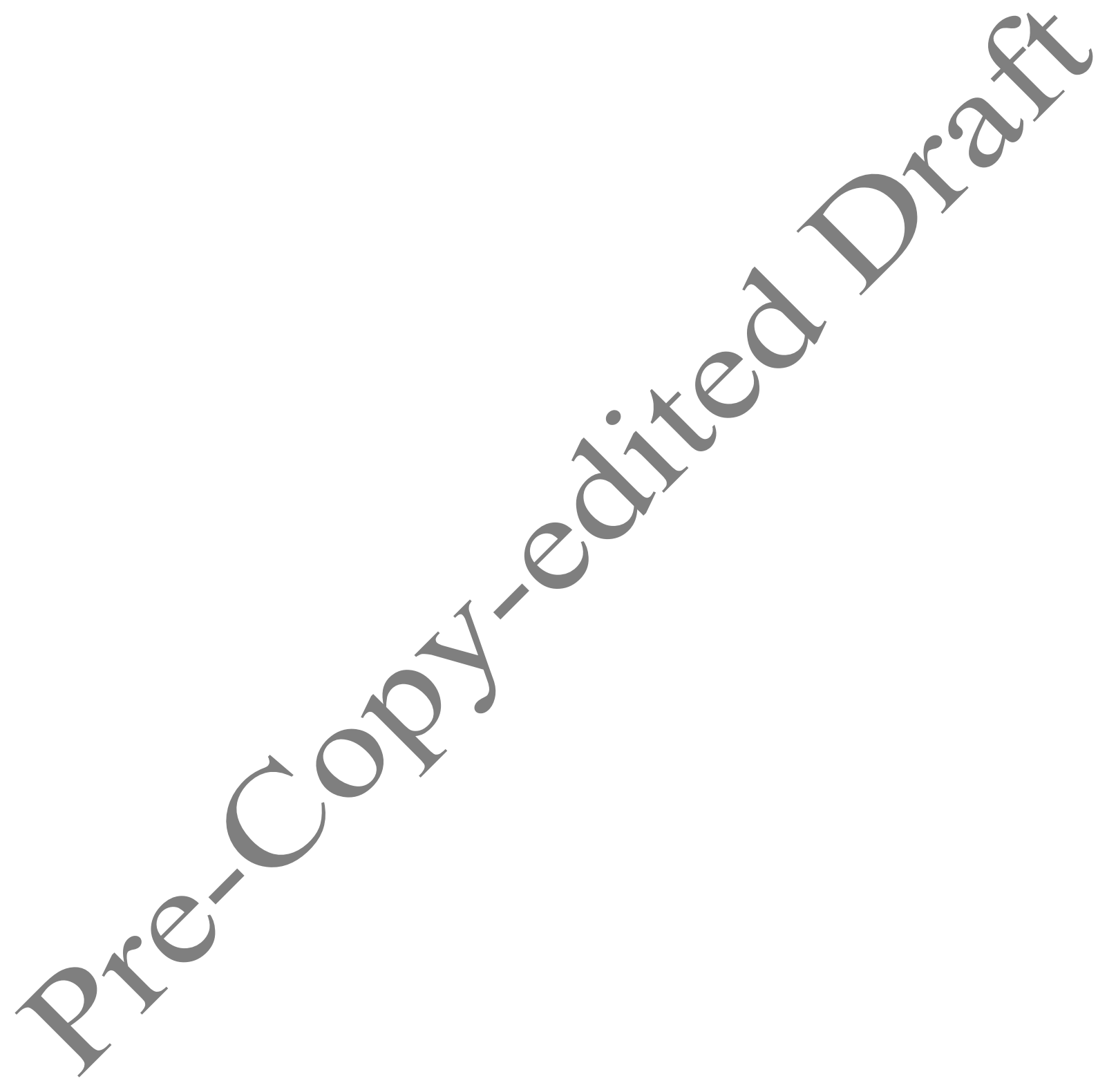


Sample 2. The results from the multi-level analyses for perspective taking can be seen in Table 3. The linear and quadratic effects of political orientation were significant, such that conservative participants reported lower levels of perspective taking compared to liberal participants. There was a significant political orientation $\times$ community ideology interaction predicting perspective taking. As seen in Figure 2a, perspective taking was higher among liberals living in areas with lower support for McCain compared to liberals living in areas with higher support for McCain. Perspective taking was also higher for conservatives living in areas with higher support for McCain and lower for conservatives living in areas with loyer support for McCain. Lower levels of perspective taking were particularly present among conservatives living in areas with lower support for McCain.

Table 3. Multi-level models predicting perspective taking

\begin{tabular}{|c|c|c|c|c|c|c|c|}
\hline & $b$ & $S E$ & $Z$ & $p$ & $95 \%$ & $\mathrm{II}(\mathrm{B})$ & \\
\hline Intercept & 47.761 & .541 & 88.259 & $<.001$ & LB & UB & $r$ \\
\hline Political Orientation & -1.450 & 168 & -8.638 & $<.001$ & -1.779 & -1.121 & -.04 \\
\hline Community Ideology & & .96 & 1.678 & .093 & -.055 & .711 & .01 \\
\hline Pol Orientation $\times$ Comm Ideol & .417 & .41 & 2.959 & .003 & .141 & .693 & .04 \\
\hline Political Orientation $^{2}$ & & .132 & -6.222 & $<.001$ & -1.081 & -.563 & -.09 \\
\hline Community Ideology ${ }^{2}$ & & .103 & .987 & .323 & -.100 & .302 & .01 \\
\hline Age & .010 & .009 & 1.068 & .286 & -.008 & .029 & .02 \\
\hline Gender & -.588 & .148 & -4.247 & $<.001$ & -.860 & -.317 & -.06 \\
\hline Education & .275 & .068 & 4.054 & $<.001$ & .142 & .408 & .06 \\
\hline
\end{tabular}

Note. Gender: -1s Female, 1: Male. 


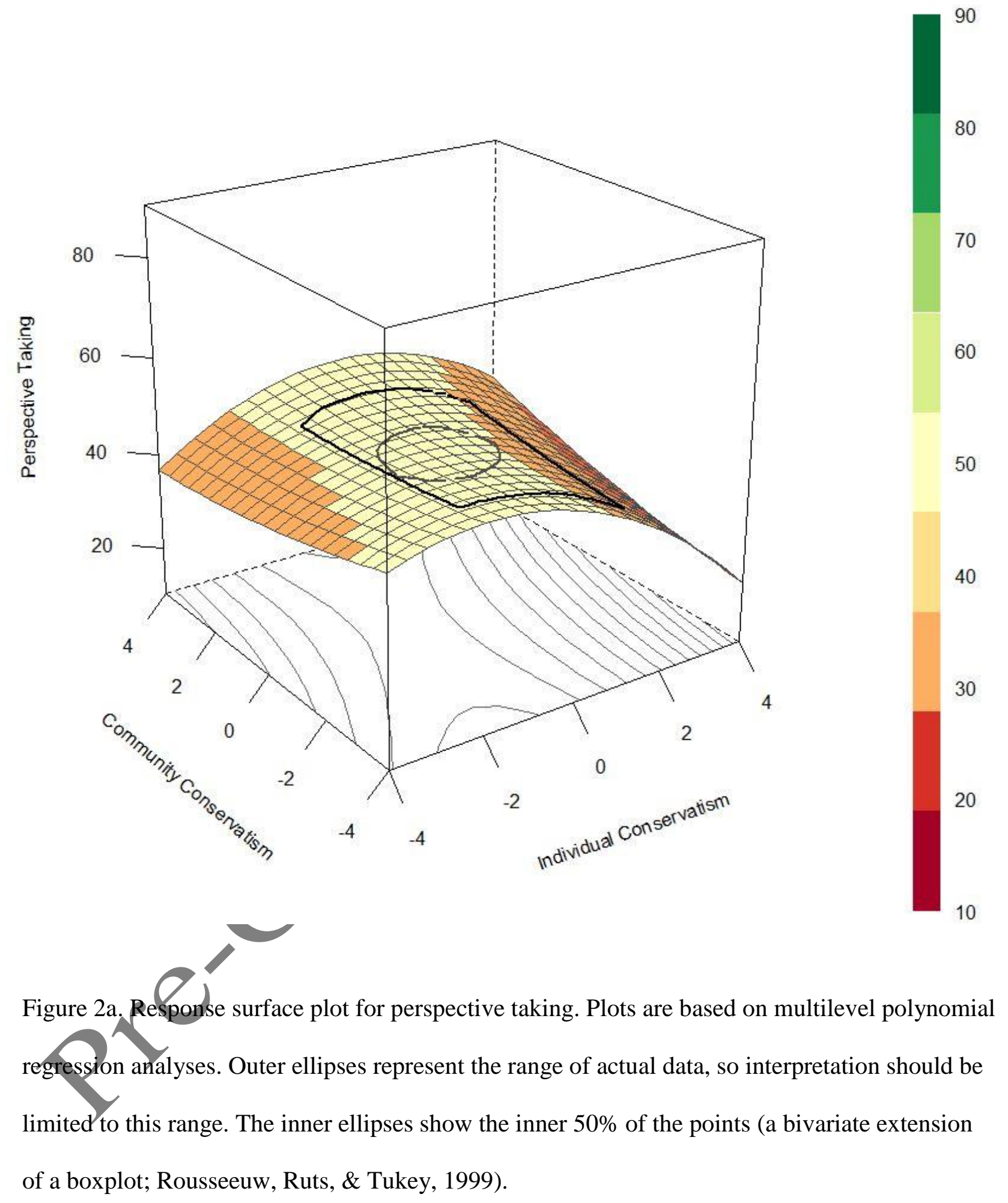


The results from the multi-level models predicting empathic concern can be seen in Table 4. The linear and quadratic effects of political orientation were significant, such that conservative participants (compared to liberal participants) reported lower levels of empathic concern (see Figure 2b). The linear effect of community ideology was significant as well, such that participants living in areas with higher levels of McCain support reported higher empathic concern compared to participants living in areas with lower levels of McCain support. The political orientation $\times$ community ideology interaction was not significant.

Table 4. Multi-level models predicting empathic concern

\begin{tabular}{|c|c|c|c|c|c|c|c|}
\hline & $b$ & $S E$ & $z$ & \multicolumn{3}{|c|}{$95 \% \mathrm{CI}(B)$} & \multirow[b]{2}{*}{$r$} \\
\hline Intercept & 44.192 & & 85.874 & $<.001$ & LB & UB & \\
\hline Political Orientation & -2.017 & & -12.674 & $<.001$ & -2.329 & -1.705 & -.18 \\
\hline Community Ideology & .386 & & 2.060 & .039 & .019 & .753 & .03 \\
\hline Pol Orientation $\times$ Comm Ideology & .063 & 33 & .470 & .638 & -.199 & .324 & .01 \\
\hline Political Orientation ${ }^{2}$ & .532 & .125 & 4.251 & $<.001$ & .287 & .778 & .06 \\
\hline Community Ideology ${ }^{2}$ & .026 & .100 & .263 & .793 & -.170 & .223 & .001 \\
\hline Age & .082 & .009 & 9.114 & $<.001$ & .064 & .100 & .13 \\
\hline Gender & & .131 & -15.120 & $<.001$ & -2.238 & -1.724 & -.21 \\
\hline Education & & .064 & .775 & .438 & -.076 & .176 & .01 \\
\hline
\end{tabular}

Note. Gender: -1: Female, 1: Male. 


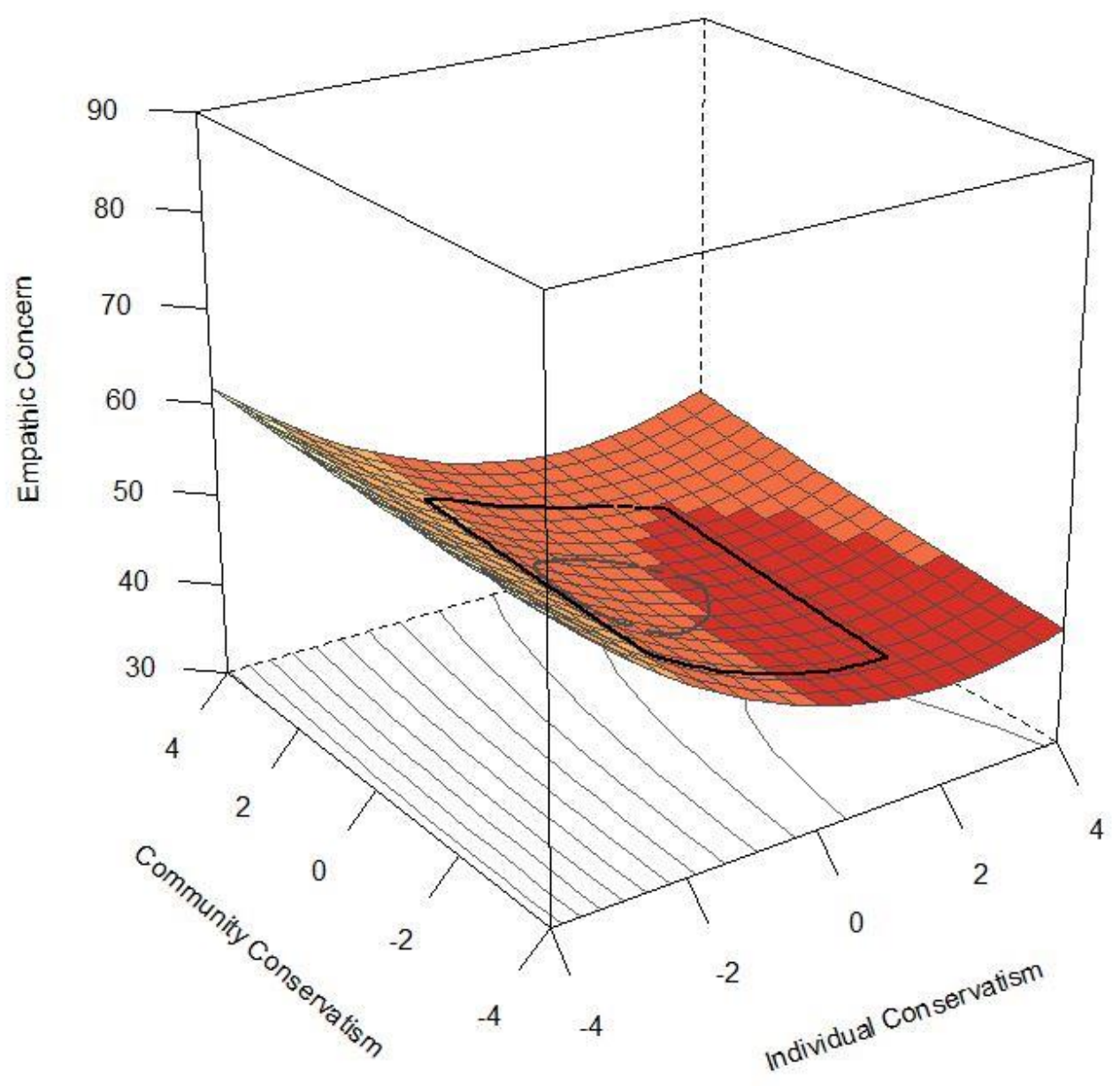

Figure 2b. Response surface plot for empathic concern. Plots are based on multilevel polynomial regression analyses. Outer ellipses represent the range of actual data, so interpretation should be limited to this range. The inner ellipses show the inner $50 \%$ of the points (a bivariate extension of a boxplot; Rousseeuw, Ruts, \& Tukey, 1999). 


\section{Discussion}

The findings from the current study reveal that living among politically dissimilar others has a psychological effect on people - they find it difficult depending on others and taking the perspective of others. Attachment avoidance has been linked to an assortment of negative outcomes for both individuals and their relationships (Mikulincer \& Shaver, 2007); perspective taking has been associated with a wide array of positive outcomes as well (Davis, 1983; Konrath, O'Brien, \& Hsing, 2011). The ideological misfit effects were not found for attachment anxiety or empathic concern. As such, living among politically dissimilar others has the potential to shape some of the dispositions of individuals which then affect how the relate to others.

One major strength of the current study is that we reled on multiple sources of data which, in combination, predicted how people across the political spectrum interacted with others. Self-reported ideology was linked with voting records from the local community to predict dispositions toward others. Our study did not directly test how isolated one-on-one interactions with politically dissimilar others then immediately affects behavior with other people. Rather, we used survey data of individuals of different political ideologies living in a variety of different communities to assess how they approached relationships more generally. Further, these effects were found over-and-above the contribution of general political ideology and only emerge when individual's ideology was at odds with the prevailing ideology of the community in which that individual lived. The study design precludes demand characteristics as participants were not instructed to think about how they fit with their current environment - they merely filled out questionnaires about their attachment orientation and empathy. The current study is also one of the few to examine how local ecology affects dispositions toward others among adults (Simpson \& Belsky, 2008). 
How exactly does living among people we disagree with affect how we approach relationships then? Extant research on the mechanisms explaining why individuals differ across geographic places suggests a few explanations (Rentfrow et al., 2008). One mechanism is that people with certain dispositions move to a particular area that fits with them psychologically. This mechanism would suggest that individuals who have a difficulty depending on and connecting with others would seek out environments where people disagree with them. Indeed, there is some evidence that individuals seek out relationships that confirm their existing beliefs about other people (Frazier, Byer, Fischer, Wright, \& DeBord, 1996). However, with respect to residential mobility, this explanation seems unlikely as political mismatching most often predicts mobility away from a politically dissimilar environment and toward politically similar environments (McDonald, 2011; Motyl, 2014; Motyl et al., 2014; Tam Cho et al., 2013).

Another suggested mechanism—-social influence - is a much more likely candidate. The mechanism would suggest that the social environments - and the other people living in themshape how they behave over time. Living in a hostile interpersonal setting shapes individuals to have dispositions where they are ess likely to psychologically connect with other people. There is also a considerableamount of evidence that people are more prejudiced toward politically dissimilar others (Iyengar \& Westwood, 2015), deny them employment opportunities (Gift \& Gift, 2014), dehumanize them (O’Brien \& Ellsworth, 2012), and discriminate against them more generally (Brandt, Reyna, Chambers, Crawford, \& Wetherell, 2014; Chambers, Schlenker, \& Collisson, 2013; Crawford et al., 2013; Crawford \& Pilanski, 2014; Wetherell, Brandt, \& Reyna, 2013). The fact that ideological misfit diminishes interpersonal orientation could therefore be a byproduct of reacting to how they are being treated in these environments. This explanation is much more consistent with research on the malleability of interpersonal behavior (Caspi \& 
Roberts, 1999; Chopik, Edelstein, \& Fraley, 2013; Eisenberg et al., 1999; Hudson, Fraley, Brumbaugh, \& Vicary, 2014; Roberts, Wood, \& Smith, 2005). In the current study, rather than individuals assimilating or altering their dispositions to be more similar to those in their social environment (Asch, 1951), they are withdrawing from relationships more generally. A fascinating question for future research then is whether the link between social influence and interpersonal behavior only occurs after living an area for an extended period of timeor can occur after just a few brief interactions with people you disagree with (Kang \& Kwak, 2003). For example, people initially ostracized by politically dissimilar others might double their efforts to connect with the people around them, which would be a prediction made by research on social exclusion (Hartgerink, van Beest, Wicherts, \& Williams, 2015). Nevertheless, repeated rejection by dissimilar others might ultimately lead to changes in interpersonal orientations.

Would moving to a politically similar area change a person's disposition? Certainly feeling as though you belong to an area or social setting is associated with a variety of good outcomes, including better happiness and health (Baumeister \& Leary, 1995; Fulmer et al., 2010; Walton \& Cohen, 2011). However, residential mobility most often translates to declines in subjective well-being and little to no changes in broader dispositions (Chopik \& Motyl, 2015; Oishi, 2010). Further, political segregation reduces the contact we have with individuals who disagree with us, enhancing the possibility for future conflict, dehumanization, and a reduced ability to compromise on important matters with other groups (G. L. Cohen et al., 2007;

Crawford et al., 2013; Motyl et al., 2014). Thus, in prescribing solutions for why political misfits are less comfortable connecting with others, it is worth acknowledging that although ideological segregation may promote greater individual well-being, it may increase political hostility and disagreements at the broader intergroup level. 


\section{Limitations}

Despite the current study's strengths and implications, there are some limitations that must be noted.

First, consistent patterns were not found across all indicators of interpersonal functioning measured. Specifically, the effects of ideological fit were most evident for attachment avoidance and perspective taking. The effects of ideological fit were not present for attachment anxiety and empathic concern. Perhaps the ability to depend on others (i.e., attachmentavoidance) and take another person's perspective (i.e., perspective taking) are more malleable to the effects of living among politically dissimilar others as they involve directly engaging with people in the environment. Perhaps being concerned about whether other people are available (i.e., attachment anxiety) and feeling sympathy for the misfortune of others (i.e., empathic concern) are more resilient to misfit environments as these are more "internal" processes that can occur without direct engagement with other people. Although these explanations are entirely speculative and post-hoc, future research can examine the exact ways in which living among politically dissimilar others affects how people relate to individuals in their social environments. Until researchers are able to retiably demonstrate that some aspects of interpersonal orientation are more affected by ideological fit — and the mechanisms underlying these effects—results from the current study should be interpreted with caution.

Second, many of the effects in the current study are relatively small in magnitude. With large sample sizes, smaller effects can be captured and more precise effect sizes can be estimated. However, the large sample sizes may yield findings that are statistically significant but of little practical significance (J. Cohen, 1990). Therefore, findings should be interpreted in light of how constructs operate in the real world and how they may accumulate after living in a 
politically similar/dissimilar area over larger stretches of time. Although identifying associations between ideological fit and interpersonal orientations is important, future research can focus on the development and changes in interpersonal orientations of people living in these environments.

Third, the current study is entirely correlational in nature. Although we attempted to rule out alternative explanations by drawing on multiple data sources and controlling for important covariates (e.g., age, gender, education), causality ultimately could not be determined. Thus, the effects we observed in the current study could be the result of some equally plausible alternative explanation. Of course, it is impractical to randomly assign individuals to live among politically similar or dissimilar others. Nevertheless, future research can develop experimental approaches to assessing ideological fit to clarify the causal properties of the current study and examine the mechanistic processes that lead to changes in interpersonal orientation (see Motyl, 2014; Motyl et al., 2014, for examples of experimental approaches of ideological fit). A nationally representative sample would also be úseful for future research. The current study is also limited by drawing from online convenience samples that came from primarily liberal participants and people living in areas with fewer Republican voters. Research questions about ideological fit should be examined in more representative samples. Also, there are likely individual differences in how much ideological fit affect interpersonal orientation that the current study did not fully capture. Future research can also identify moderators of these associations to see if ideological fit enhancesinterpersonal orientation more so under different circumstances. Identifying more strongly with one's political party might lead to greater ideological fit effects compared to someone who is not as invested in their political identity. 


\section{Conclusion}

The current study's findings demonstrate that living among politically dissimilar others is associated with a difficulty depending on and taking the perspectives of other people. As individuals continue to segregate themselves into geographic areas according to political ideology, it is important to understand the psychological states of individuals living in discordant communities. Sartre famously wrote, "Hell is other people" in his play No Exit. Indeed, the social environment around us is often a large component of our happiness and how we behave, particularly when we are at odds with the people around us. Thus, hell can be other people, especially if those other people hold different political views than you. 


\section{References}

Asch, M. J. (1951). Nondirective teaching in psychology: An experimental study. Psychological Monographs: General and Applied, 65(4), i-24.

Bar-Tal, D., \& Halperin, E. (2010). Overcoming psychological barriers to peacemaking: The influence of beliefs about losses. In M. Mikulincer \& P. R. Shaver (Eds.), Prosocia motives, emotions, and behavior: The better angels of our nature. (pp. 431-448).

Washington, DC, US: American Psychological Association.

Bar-Tal, D., Halperin, E., \& Pliskin, R. (2015). Why is it so difficult to resolve intractable conflicts peacefully? A sociopsychological explanation. In M. Galluccio (Ed.), Handbook of international negotiation: Interpersonal, intercultural, and diplomatic perspectives. (pp. 73-92). Cham, Switzerland: Springer Interhational Publishing.

Baumeister, R. F., \& Leary, M. R. (1995). The need to belong: Desire for interpersonal attachments as a fundamental human motivation. Psychological Bulletin, 117(3), 497529.

Belsky, J., Steinberg, L., \& Draper, P. (1991). Childhood experience, interpersonal development, and reproductire strategy: An evolutionary theory of socialization. Child Development, $62(4), 647-670$.

Bleidorn, W., Schönbrodt, F., Gebauer, J. E., Rentfrow, P. J., Potter, J., \& Gosling, S. D. (2016). To Live Among Like-Minded Others: Exploring the Links Between Person-City Personality Fit and Self-Esteem. Psychological Science, 27(3), 419-427.

Brandt, M. J., Reyna, C., Chambers, J. R., Crawford, J. T., \& Wetherell, G. (2014). The Ideological-Conflict Hypothesis: Intolerance Among Both Liberals and Conservatives. Current Directions in Psychological Science, 23(1), 27-34. 
Carney, D. R., Jost, J. T., Gosling, S. D., \& Potter, J. (2008). The secret lives of liberals and conservatives: Personality profiles, interaction styles, and the things they leave behind. Political Psychology, 29(6), 807-840.

Caspi, A., \& Roberts, B. W. (1999). Personality continuity and change across the life course. In L. A. Pervin \& O. P. John (Eds.), Handbook of personality: Theory and research (2nd) ed.). (pp. 300-326). New York, NY US: Guilford Press.

Chambers, J. R., Schlenker, B. R., \& Collisson, B. (2013). Ideology and Prejudice: The Role of Value Conflicts. Psychological Science, 24(2), 140-149.

Chinni, D., \& Gimpel, J. (2010). Our patchwork nation: The surprising truth about the "real" America. The 12 community types that make up our nation. New York: Gotham Books.

Chisholm, J. S. (1993). Death, hope, and sex: Life-history theory and the development of reproductive strategies. Current Anthropology, 34(1), 1-24.

Chopik, W. J., Edelstein, R. S., \& Fraley, R. C.(2013). From the cradle to the grave: Age differences in attachment from early adulthood to old age. Journal of Personality, 81, 171-183.

Chopik, W. J., \& Moty1, M.(2015). Change across the Lifespace: How geographic differences in personality are tied to relationships, environmental fit, and the adoption of social roles over time. Paper presented at the Association for Research in Personality, St. Louis, MO.

Cohen, G. L., Sherman, D. K., Bastardi, A., Hsu, L., McGoey, M., \& Ross, L. (2007). Bridging the partisan divide: Self-affirmation reduces ideological closed-mindedness and inflexibility in negotiation. Journal of Personality and Social Psychology, 93(3), 415430. 
Cohen, J. (1988). Statistical power analysis for the behavioral sciences (2nd ed.). Hillsdale, NJ: Erlbaum.

Cohen, J. (1990). Things I have learned (so far). American Psychologist, 45(12), 1304-1312.

Crawford, J. T., Modri, S. A., \& Motyl, M. (2013). Bleeding-heart liberals and hard-hearted conservatives: Subtle political dehumanization through differential attributions of human nature and human uniqueness traits. Journal of Social and Political Psychology, (1).

Crawford, J. T., \& Pilanski, J. M. (2014). Political Intolerance, Right and Left. Political Psychology, 35(6), 841-851.

Davis, M. H. (1983). Measuring individual differences in empathy: Evidence for a multidimensional approach. Journal of Personality and Social Psychology, 44(1), 113 126.

Edwards, J. R. (2002). Alternatives to difference scores: Polynomial regression analysis and response surface methodology. In F. Drasgow \& N. W. Schmitt (Eds.), Advances in measurement and data analysis (pp. 350-400). San Francisco: Jossey-Bass.

Edwards, J. R. (2007). Polynomial regression and response surface methodology. In C. Ostroff \& T. A. Judge (Eds.), Perspectives on organizational fit (pp. 361-372). San Francisco: Jossey-Bass.

Eisenberg, N. Guthrie, I. K., Murphy, B. C., Shepard, S. A., Cumberland, A., \& Carlo, G. (1999). Consistency and development of prosocial dispositions: a longitudinal study. Child Development, 70(6), 1360-1372.

Florida, R. (2008). Who's your city? How the creative economy is making where to live the most important decision of your life. New York: Basic Books. 
Fraley, R. C., Waller, N. G., \& Brennan, K. A. (2000). An item response theory analysis of selfreport measures of adult attachment. Journal of Personality and Social Psychology, $78(2), 350-365$.

Frazier, P. A., Byer, A. L., Fischer, A. R., Wright, D. M., \& DeBord, K. A. (1996). Adult attachment style and partner choice: Correlational and experimental findings. Personal, Relationships, 3(2), 117-136.

Fulmer, C. A., Gelfand, M. J., Kruglanski, A. W., Kim-Prieto, C., Diener,E., Pierro, A., \& Higgins, E. T. (2010). On 'feeling right' in cultural contexts: How person-culture match affects self-esteem and subjective well-being. Psychological Science, 21(11), 1563-1569.

Gift, K., \& Gift, T. (2014). Does Politics Influence Hiring? Eyidence from a Randomized Experiment. Political Behavior, 37(3), 653-675.

Hartgerink, C. H. J., van Beest, I., Wicherts, J. M., \& Williams, K. D. (2015). The ordinal effects of ostracism: A meta-analysis of 120 cyberball studies. PLoS ONE, 10(5).

Hudson, N. W., Fraley, R. C., Brumbaugh, C. C., \& Vicary, A. M. (2014). Coregulation in romantic partners' attachment styles: A longitudinal investigation. Personality and Social Psychology Butletin, 40(7), 845-857.

Iyengar, S., \& Westwood, \$. J. (2015). Fear and Loathing across Party Lines: New Evidence on Group Polarization. American Journal of Political Science, 59(3), 690-707.

Kang, N., \& Kwak, N. (2003). A multilevel approach to civic participation: Individual length of residence, neighborhood residential stability, and their interactive effects with media use. Communication Research, 30(1), 80-106. 
Kling, K. C., Ryff, C. D., Love, G., \& Essex, M. (2003). Exploring the influence of personality on depressive symptoms and self-esteem across a significant life transition. Journal of Personality and Social Psychology, 85(5), 922-932.

Konrath, S., O'Brien, E., \& Hsing, C. (2011). Changes in dispositional empathy in American college students over time: a meta-analysis. Personality and Social Psychology Review, 15(2), 180-198.

McDonald, I. (2011). Migration and sorting in the american electorate: Eyidence from the 2006 Cooperative Congressional Election Study. American Politics Research, 39(3), 512-533.

Mikulincer, M., \& Shaver, P. R. (2007). Attachment in adulthood. Structure, dynamics, and change. New York, NY, US: Guilford Press.

Motyl, M. (2014). 'If he wins, i'm moving to Canada': Ideological migration threats following the 2012 U.S. Presidential election. Analyses of Sogial Issues and Public Policy (ASAP), 14(1), 123-136.

Motyl, M. (2016). Liberals and conservatives are geographically dividing. In P. Valdesolo \& J. Graham (Eds.), Bridging (deologieal Divides: The Claremont Symposium for Applied Social Psychology: Sage Press.

Motyl, M., Iyer, R., Oishi, S., Trawalter, S., \& Nosek, B. A. (2014). How ideological migration geographically segregates groups. Journal of Experimental Social Psychology, 51, 1-14.

O'Brien, E., \& Ellsworth, P. C. (2012). More than skin deep: Visceral states are not projected onto dissimilar others. Psychological Science, 23(4), 391-396.

Oishi, S. (2010). The psychology of residential mobility: Implications for the self, social relationships, and well-being. Perspectives on Psychological Science, 5(1), 5-21. 
Peugh, J. L., \& Enders, C. K. (2005). Using the SPSS Mixed Procedure to Fit Cross-Sectional and Longitudinal Multilevel Models. Educational and Psychological Measurement, $65(5), 717-741$.

Rentfrow, P. J. (2010). Statewide differences in personality: Toward a psychological geography of the United States. American Psychologist, 65(6), 548-558.

Rentfrow, P. J., Gosling, S. D., \& Potter, J. (2008). A theory of the emergence, persistence, and expression of geographic variation in psychological characteristics. Perspectives on Psychological Science, 3(5), 339-369.

Riskind, R., \& Motyl, M. (2012). The social ecology of Americancommunities: 2012.

Roberts, B. W., Wood, D., \& Smith, J. L. (2005). Evaluating Five Factor Theory and social investment perspectives on personality trait development. Journal of Research in Personality, 39(1), 166-184.

Rousseeuw, P. J., Ruts, I., \& Tukey, J. W. (1999). The Bagplot: A Bivariate Boxplot. The American Statistician, 53(4),382-387.

Schönbrodt, F. D. (2016). RSA:An R package for response surface analysis (version 0.9.10).

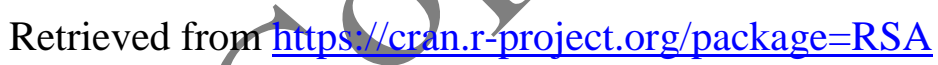

Simpson, J. A., \& Belsky, J. (2008). Attachment theory within a modern evolutionary framework. In J. Cassidy \& P. R. Shaver (Eds.), Handbook of attachment: Theory, research, and clinical applications (2nd ed.). (pp. 131-157). New York, NY US: Guilford Press.

Tam Cho, W. K., Gimpel, J. G., \& Hui, I. S. (2013). Voter migration and the geographic sorting of the American electorate. Annals of the Association of American Geographers, 103(4), 856-870. 
Walton, G. M., \& Cohen, G. L. (2011). A brief social-belonging intervention improves academic and health outcomes of minority students. Science, 331(6023), 1447-1451.

Wetherell, G. A., Brandt, M. J., \& Reyna, C. (2013). Discrimination Across the Ideological Divide: The Role of Value Violations and Abstract Values in Discrimination by Liberals and Conservatives. Social Psychological and Personality Science, 4(6), 658-667

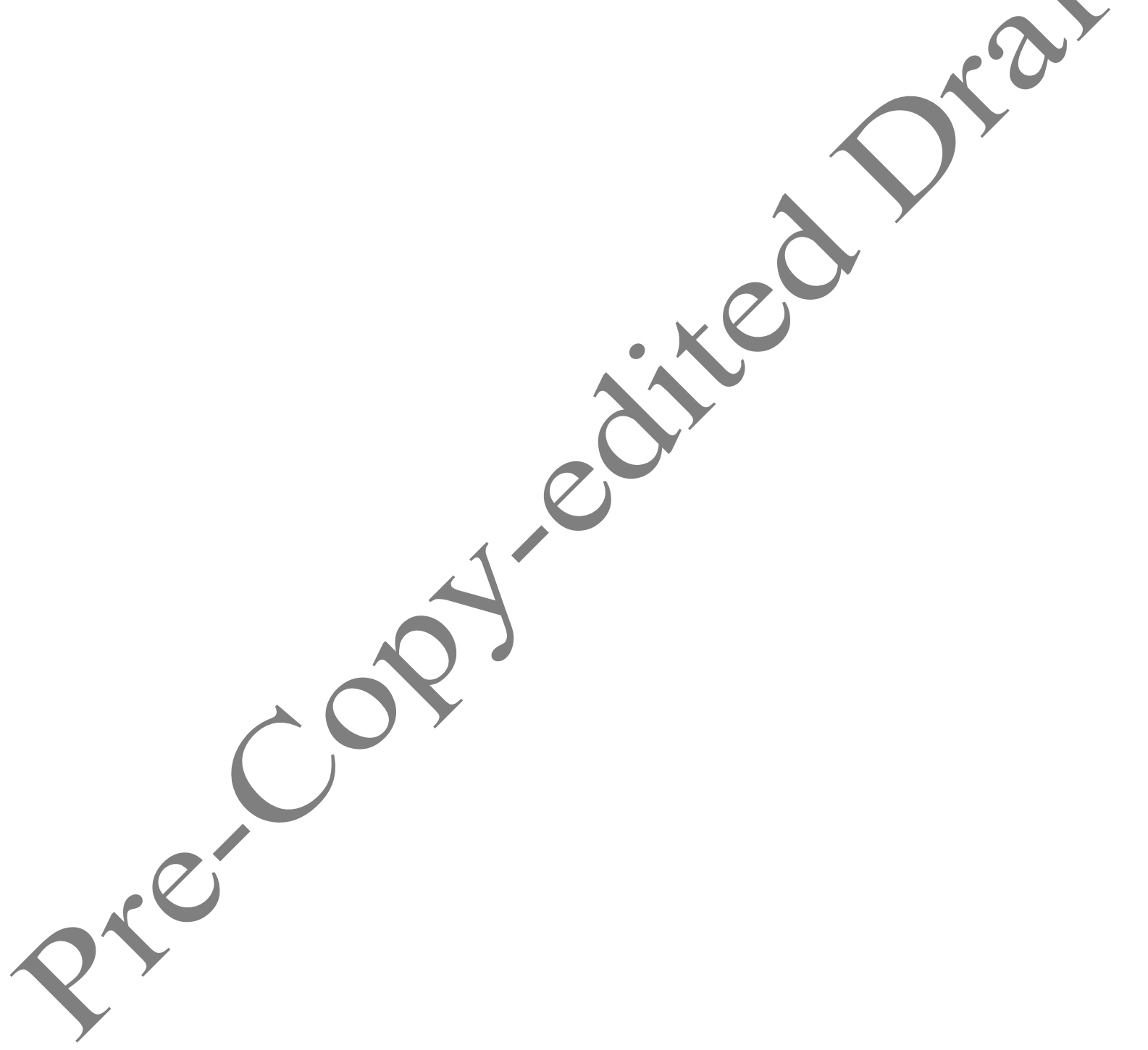

